Supporting Information

\title{
Deterministic Ferroelastic Domain Switching Using Ferroelectric Bilayers
}

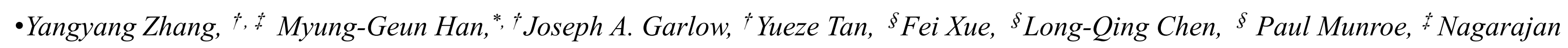
Valanoor, ${ }^{*}:$ and Yimei Zhu ${ }^{*},+$

- Condensed Matter Physics and Materials Sciences Department, Brookhaven National Laboratory, Upton, New York 11973, United States

- :School of Materials Science and Engineering, University of New South Wales, Sydney, New South Wales 2052, Australia

- ${ }^{\S}$ Department of Materials Science and Engineering, Pennsylvania State University, University Park, Pennsylvania 16802, United States 
(a)

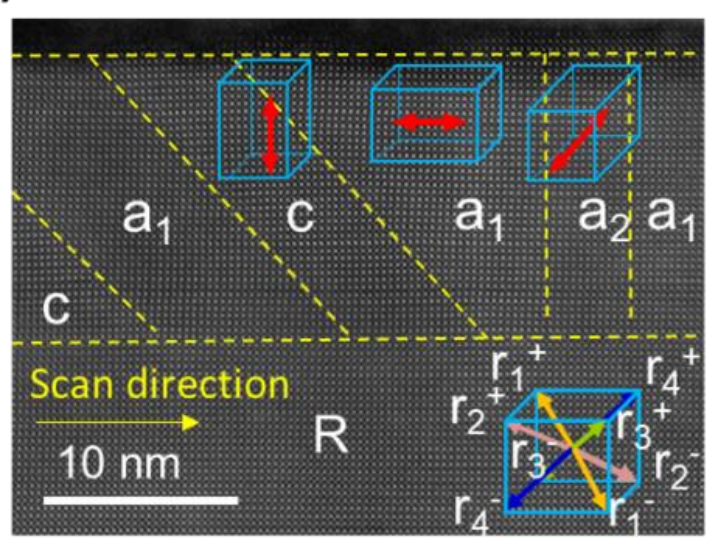

(c)

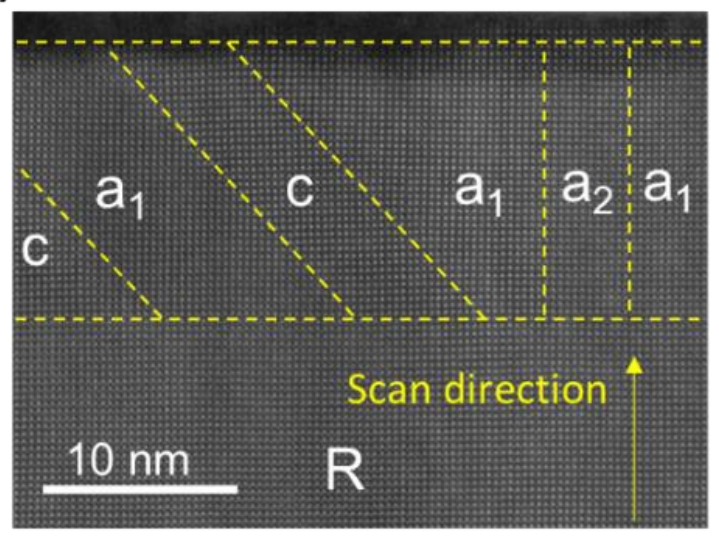

(b)

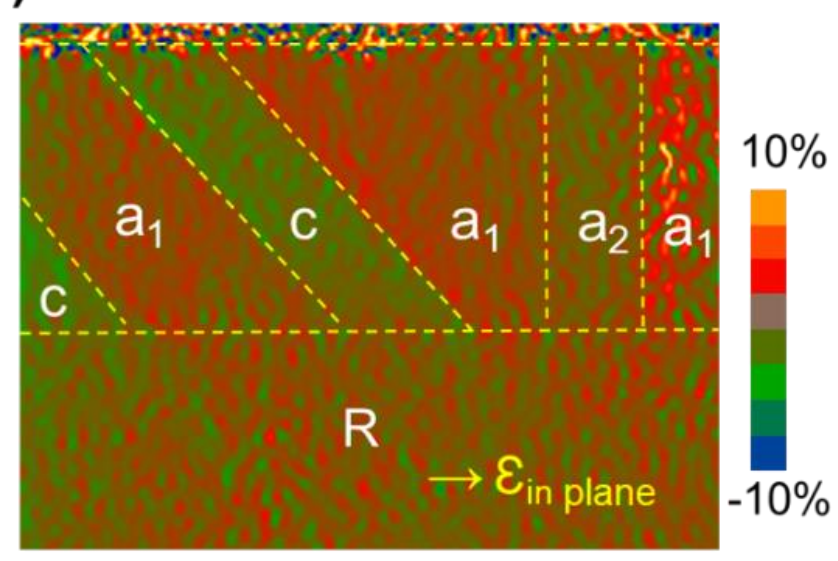

(d)

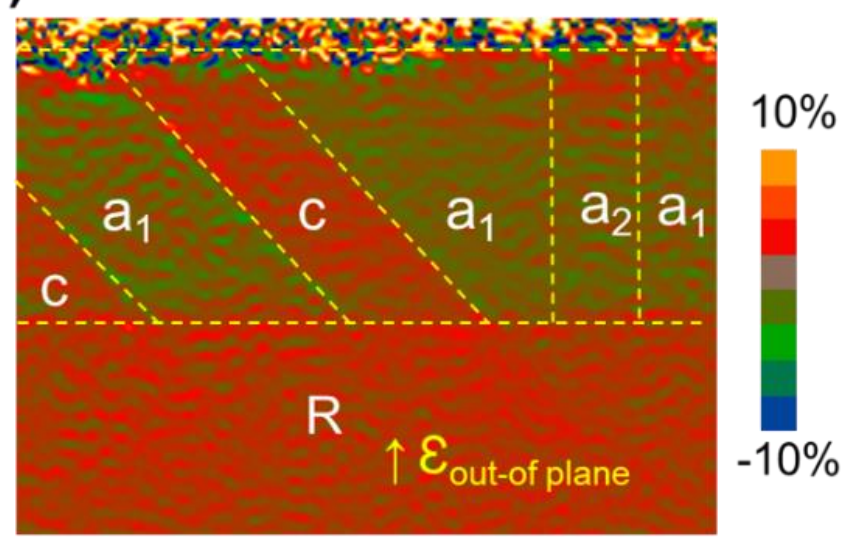

Figure S1. (a) and (c) are HAADF images captured at the same area but the scan directions rotate $90^{\circ}$ relatively. (a) is Figure $1 \mathrm{~d}$ in the main manuscript. (c) and (d) are in-plane and outof-plane strain maps obtained from (a) and (c). They are Figure $1 \mathrm{f}$ and $1 \mathrm{e}$ in the main manuscript. 


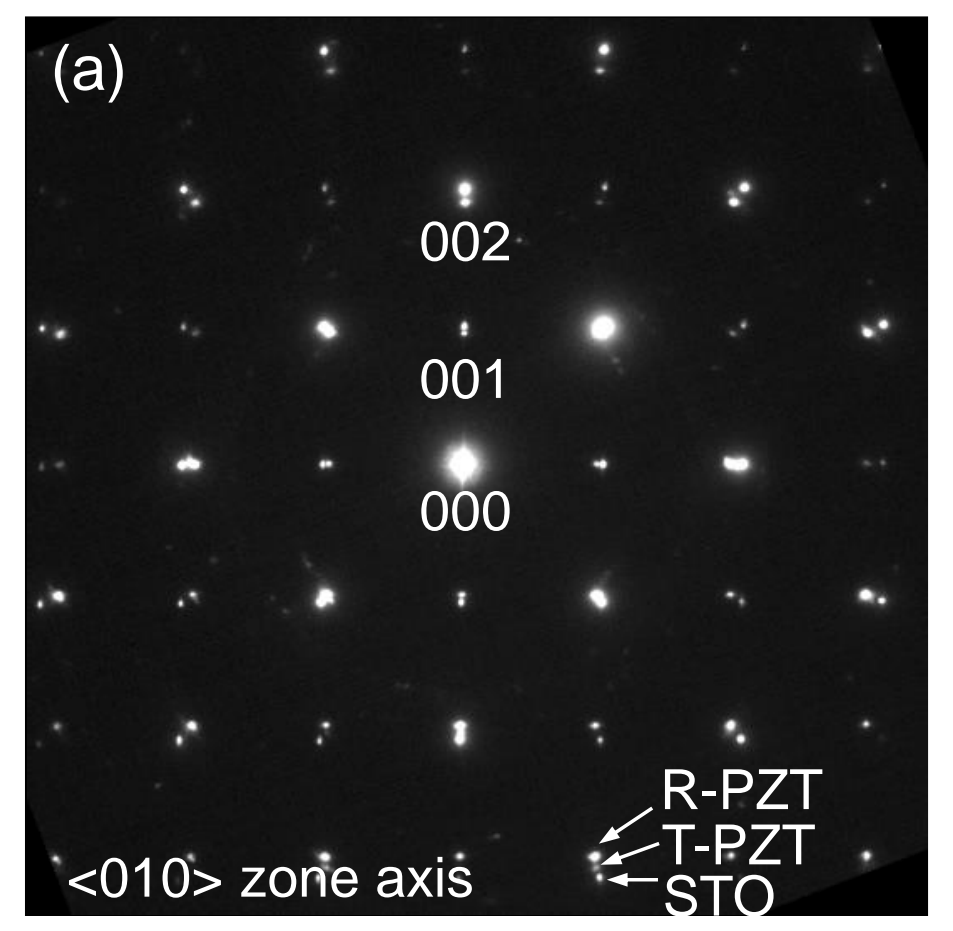

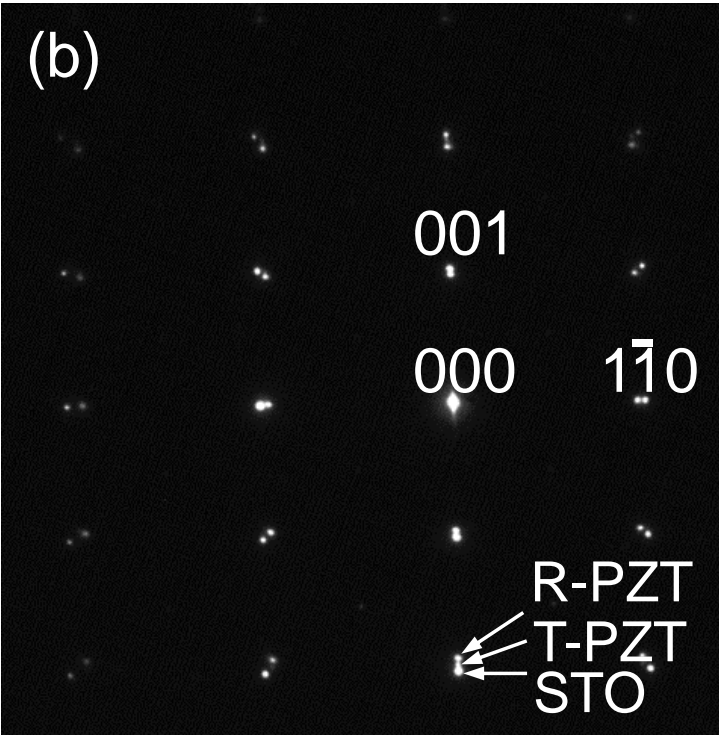

$<110>$ zone

Figure S2 SAED patterns captured from $<010>$ zone axis and $<110>$ zone axis 


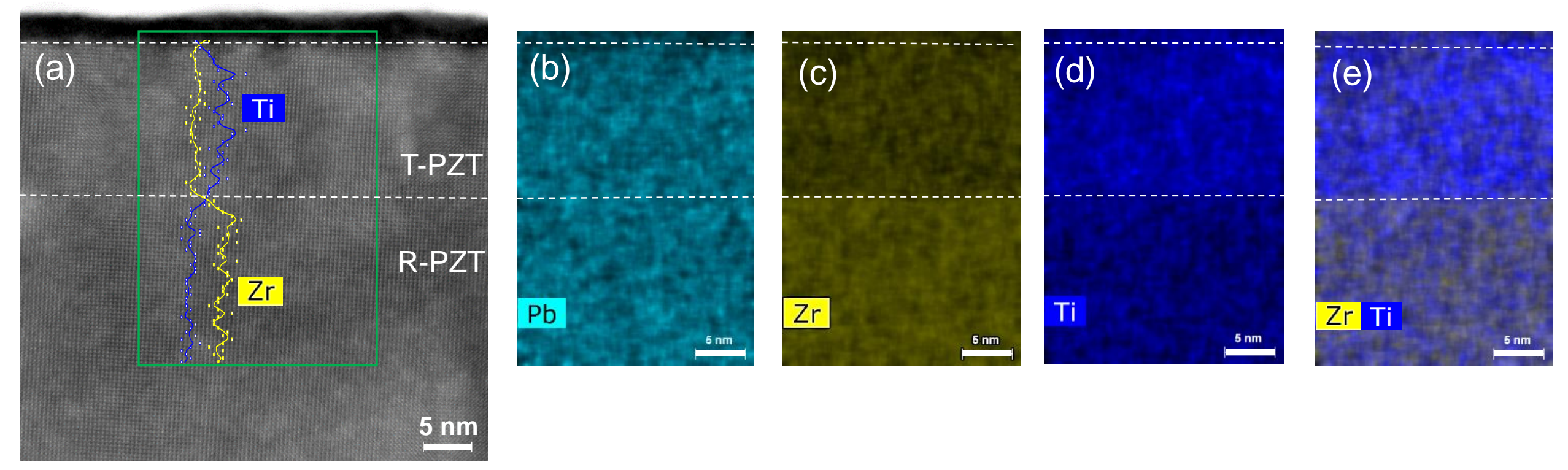

Figure S3 HAADF STEM image overlaid with EDS line scan and EDS mapping of $\mathrm{Pb}, \mathrm{Zr}$ and $\mathrm{Ti}$ 


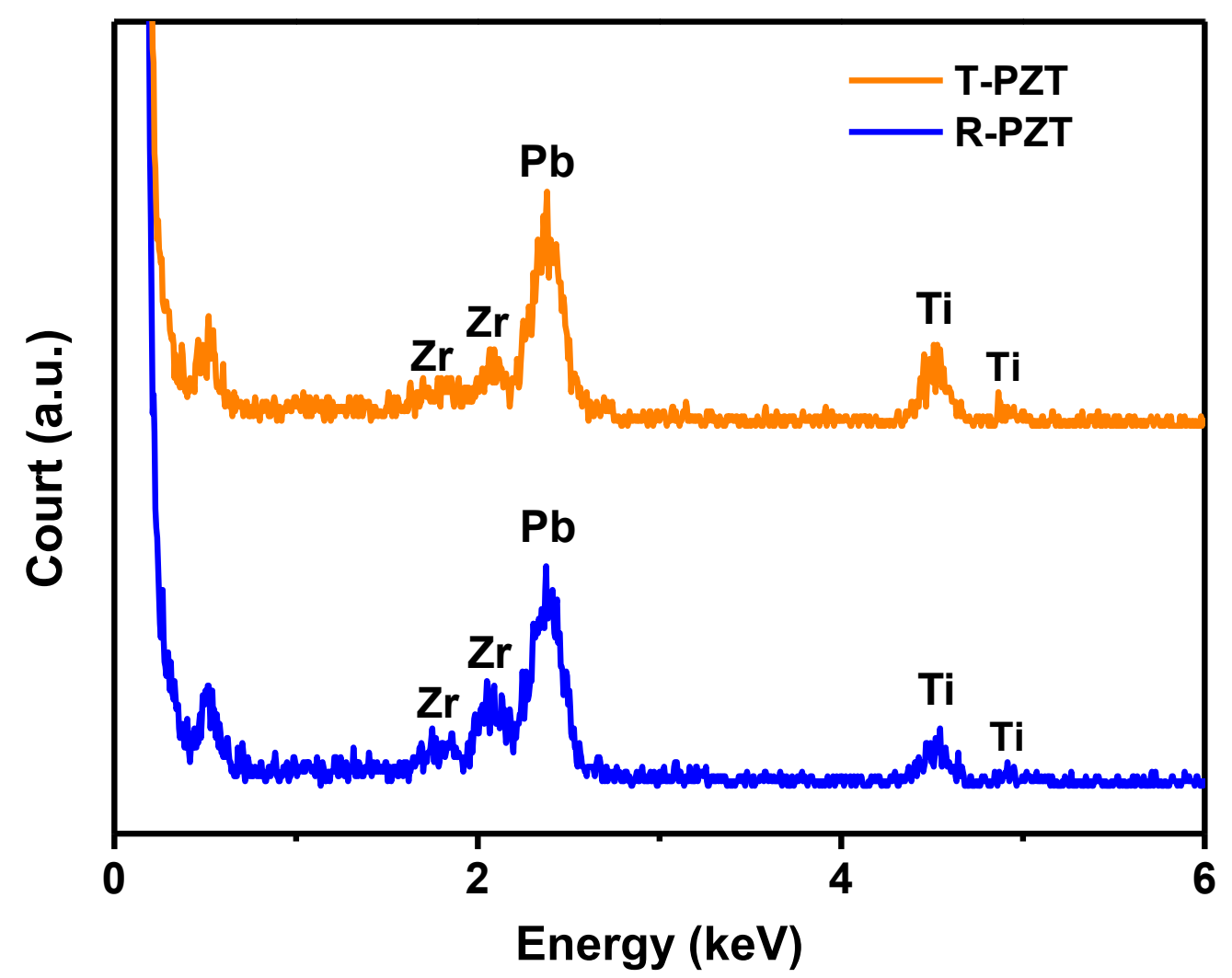

Figure S4 EDS spectra of T-PZT and R-PZT layers 
Tables S1 Quantitative analysis of chemical composition for T-PZT and R-PZT layers (Zr and Ti)

\begin{tabular}{|c|c|c|c|c|c|}
\hline \multicolumn{2}{|c|}{ Sample EDS Parameters } & $10 \mathrm{kv} 50 \mathrm{~s}$ & $10 \mathrm{kv} 100 \mathrm{~s}$ & $20 \mathrm{kv} 100 \mathrm{~s}$ & Average \\
\hline \multirow{2}{*}{$\begin{array}{l}\mathrm{PZT}(\mathrm{T}) \\
\mathrm{PbZr}_{0.8} \mathrm{Ti}_{0.2} \mathrm{O}_{3}\end{array}$} & $\mathrm{Zr} /(\mathrm{Zr}+\mathrm{Ti})$ atomic $\%$ & 19.79 & 21.49 & 19.65 & 20.31 \\
\hline & $\mathrm{Ti} /(\mathrm{Zr}+\mathrm{Ti})$ atomic $\%$ & 80.21 & 78.51 & 80.35 & 79.69 \\
\hline \multirow{2}{*}{$\begin{array}{l}\mathrm{PZT}(\mathrm{R}) \\
\mathrm{PbZr}_{0.55} \mathrm{Ti}_{0.45} \mathrm{O}_{3}\end{array}$} & $\mathrm{Zr} /(\mathrm{Zr}+\mathrm{Ti})$ atomic $\%$ & 52.10 & 54.89 & & 53.50 \\
\hline & $\mathrm{Ti} /(\mathrm{Zr}+\mathrm{Ti})$ atomic $\%$ & 47.90 & 45.11 & & 46.50 \\
\hline
\end{tabular}




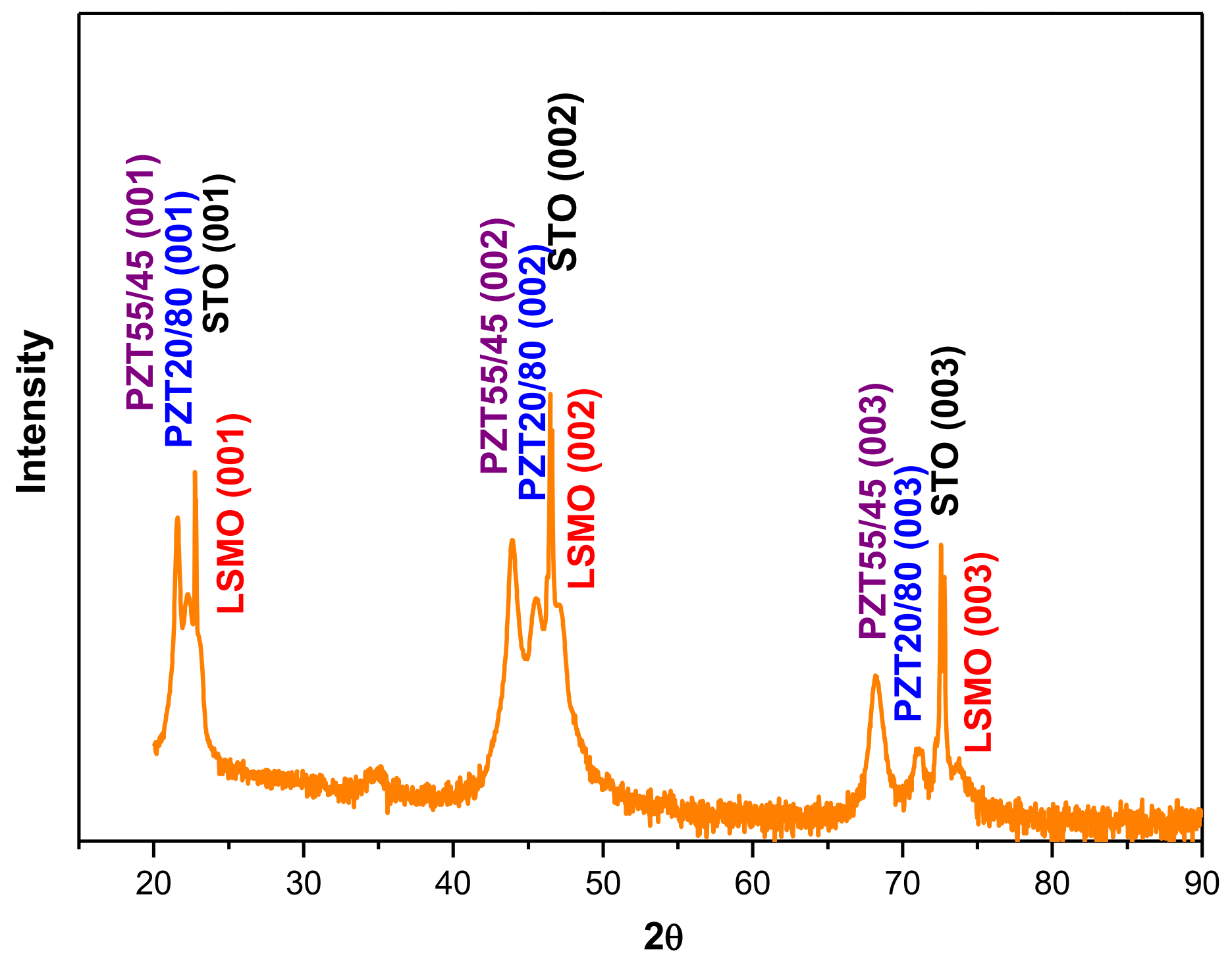

Figure S5 XRD pattern of the films T-PZT/R-PZT/LSMO/STO 

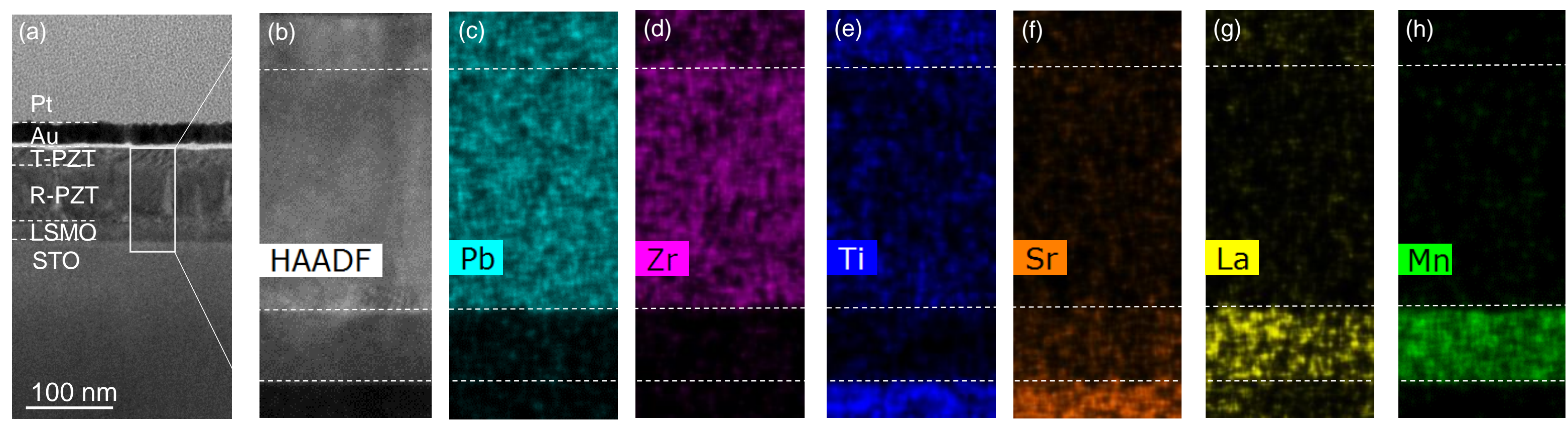

Figure S6 HAADF/STEM imaging and EDS elemental mapping 

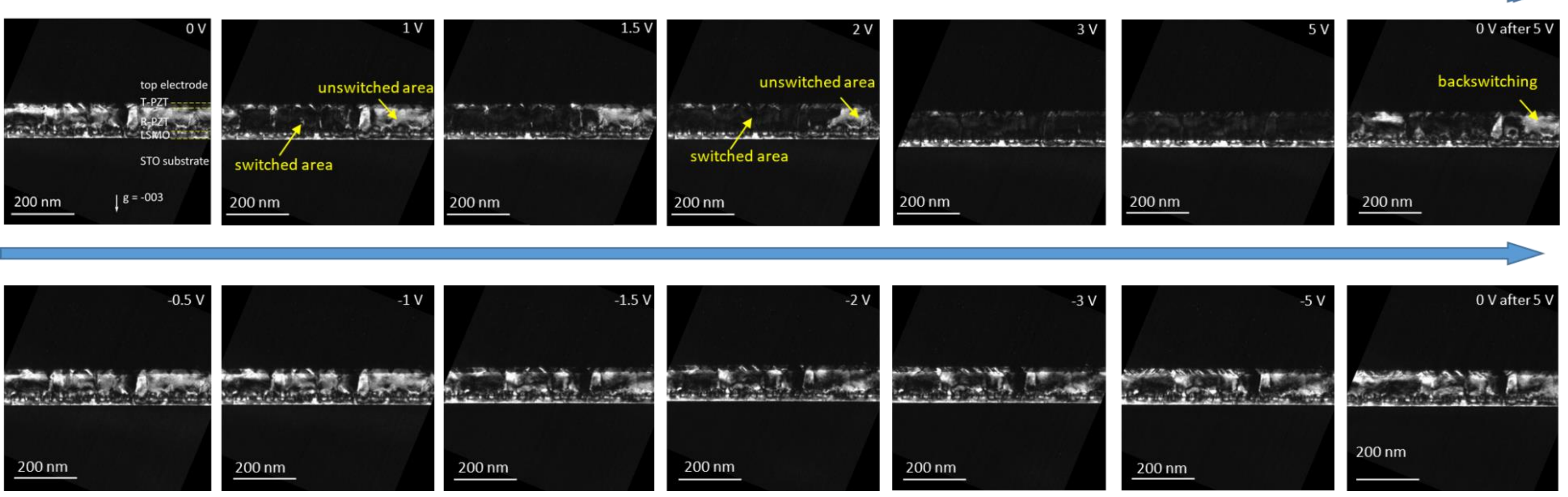

Figure S8 Switching sequence of R-PZT captured in dark-field image mode (bias is directly removed). 

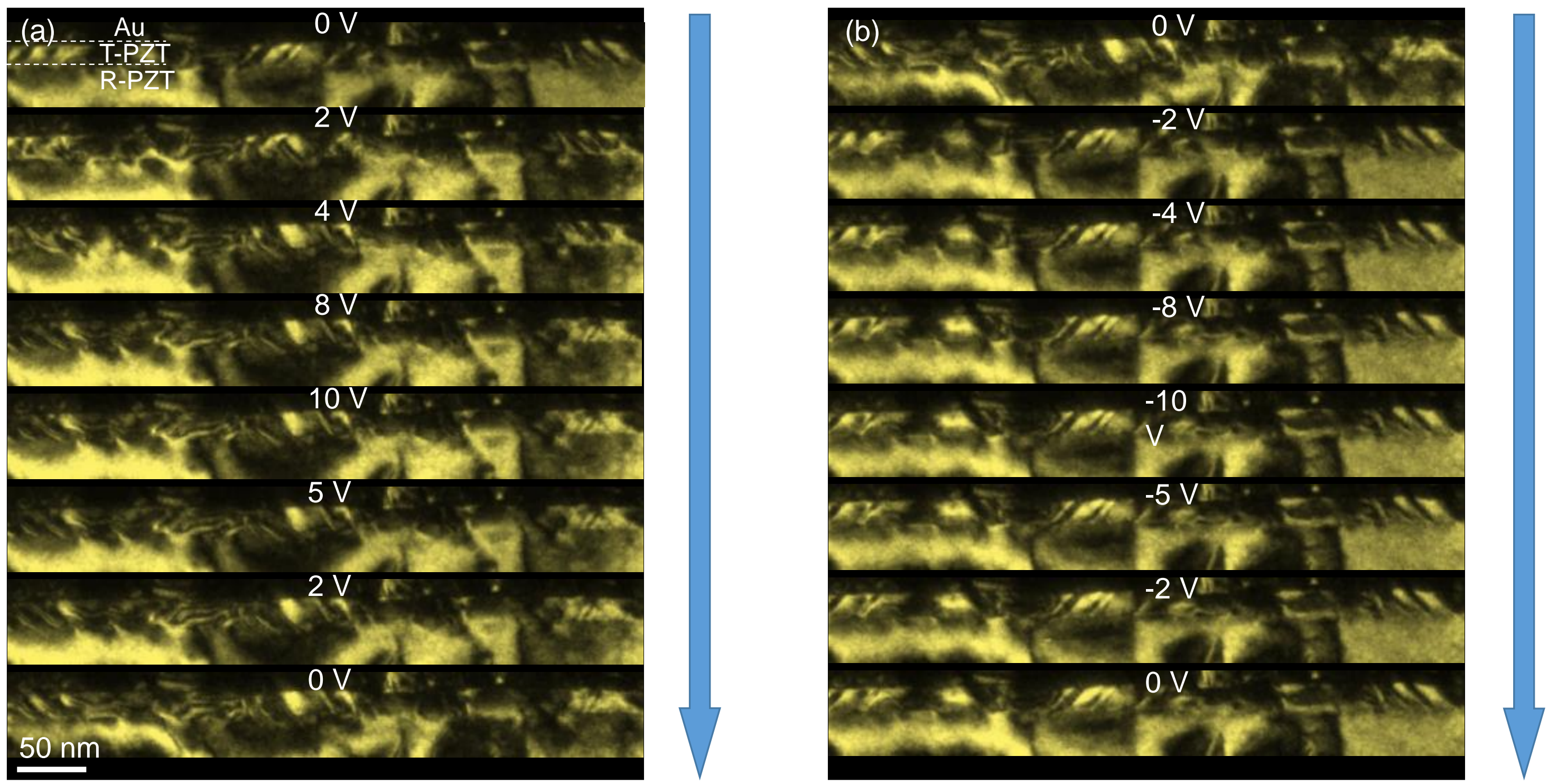

Figure S9 Switching sequence of R-PZT captured in dark-field image mode (bias is slowly removed). 

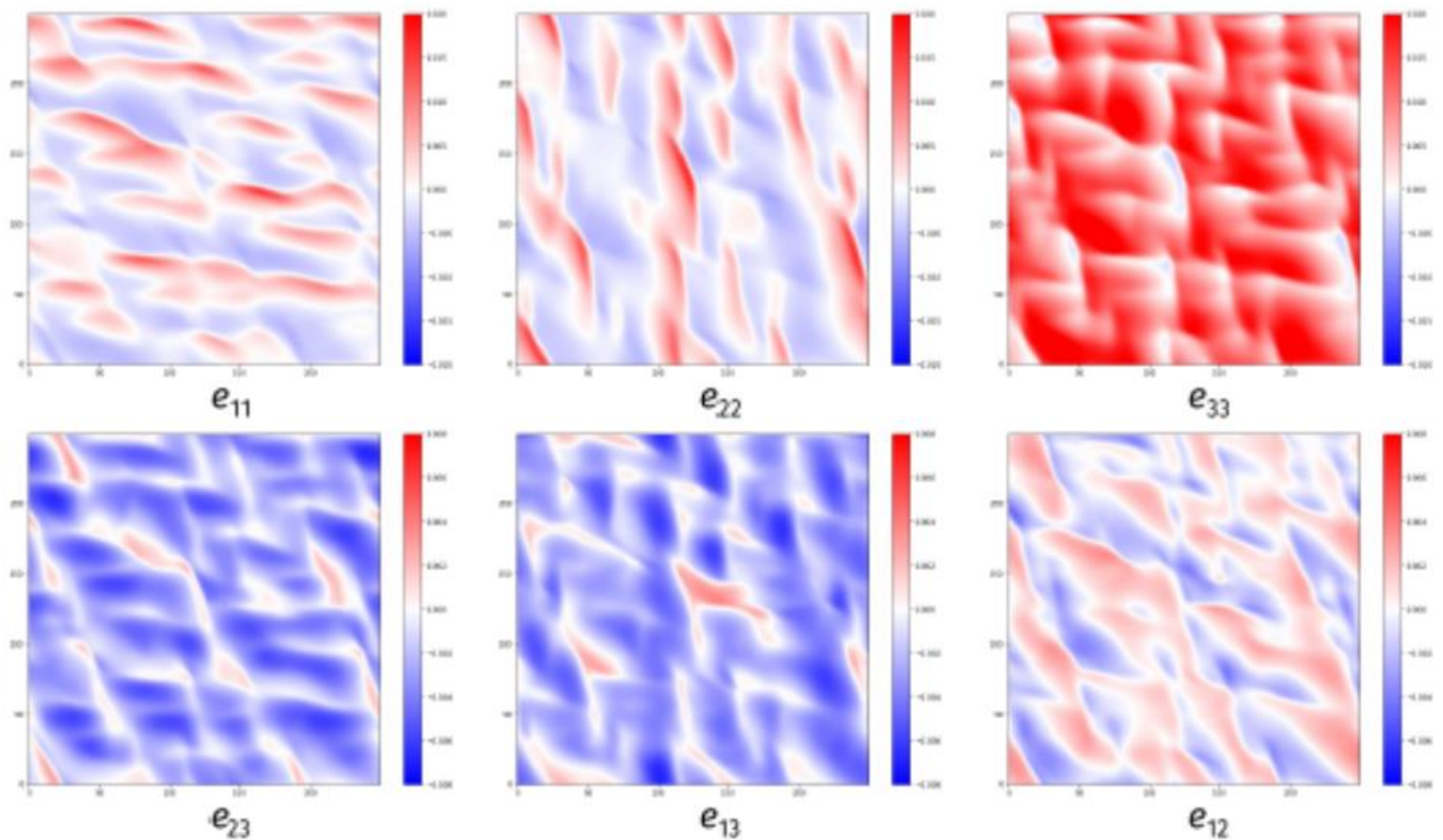

Figure S10 Simulated in-plane, out-of-plane and shear strain profiles 
(a) Initial State
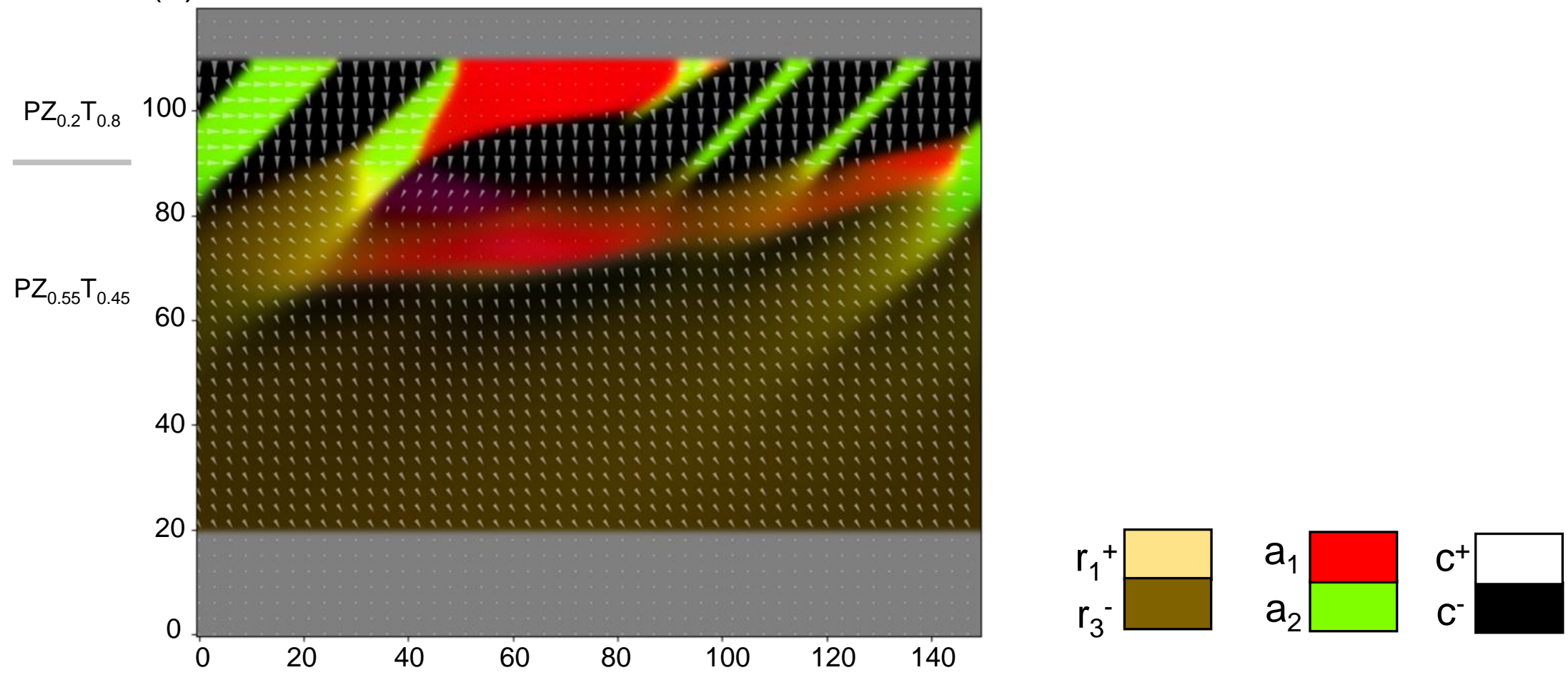

(b)

(c) Extension of $71^{\circ}$ switching

(d) Domain wall reorientation

(e)

Final State
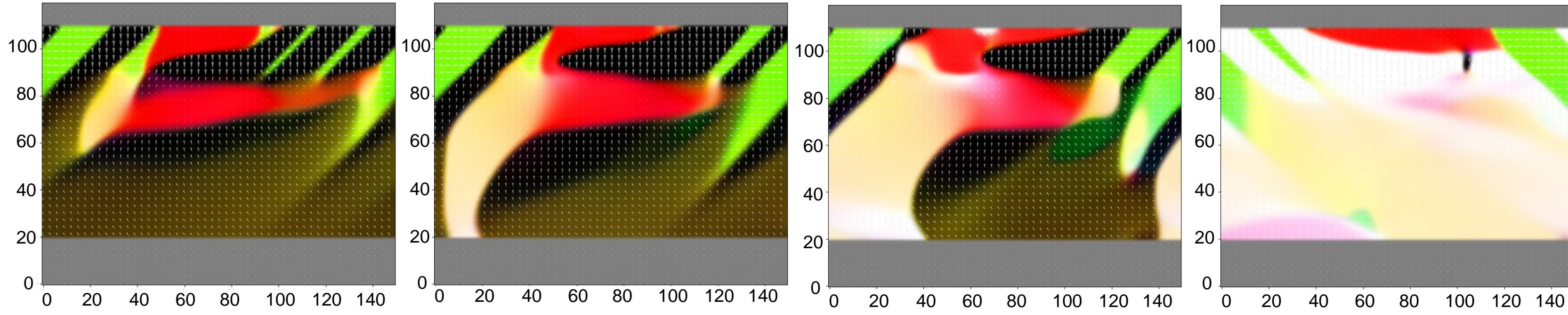

Figure S11 Simulated Switching Sequence 
Table S2 Calculation of the lattice parameters of the T layer and R layer in the bilayer (calibrated with lattice parameters of STO substrate)

\begin{tabular}{|c|c|c|c|c|c|c|c|c|c|}
\hline \multicolumn{10}{|c|}{ SAED 100 zone axis } \\
\hline \multirow{2}{*}{ hkl } & \multirow{2}{*}{$\begin{array}{l}2 * \text { radius of } \\
\text { STO (mrad) }\end{array}$} & \multirow{2}{*}{$\begin{array}{l}2 * \text { radius of } \\
\text { PZT (mrad) }\end{array}$} & \multirow{2}{*}{ d-spacing $(\AA ̊)$} & \multicolumn{3}{|c|}{ a-domain } & \multicolumn{3}{|c|}{ R-PZT } \\
\hline & & & & a $(\AA ̊)$ & $b(\AA ̊)$ & $c(\AA)$ & a $(\AA ̊)$ & $\mathrm{b}(\AA ̊)$ & $c(\AA ̊)$ \\
\hline $001 \mathrm{R}$ & 13.181 & 12.507 & 4.115 & & & & & & 4.115 \\
\hline $002 \mathrm{R}$ & 26.340 & 25.018 & 2.056 & & & & & & 4.111 \\
\hline $002 \mathrm{~T}$ & 26.340 & 25.742 & 1.998 & 3.996 & & & & & \\
\hline $003 \mathrm{R}$ & 39.657 & 37.562 & 1.374 & & & & & & 4.123 \\
\hline $010 R$ & 13.421 & 12.873 & 4.071 & & & & & 4.071 & \\
\hline $020 \mathrm{R}$ & 26.793 & 25.595 & 2.044 & & & & & 4.088 & \\
\hline $030 \mathrm{R}$ & 40.253 & 38.606 & 2.036 & & & & & 4.072 & \\
\hline \multicolumn{10}{|c|}{ SAED 110 zone axis } \\
\hline \multirow{2}{*}{ hkl } & $2 *$ radius of & $2 *$ radius of & \multirow{2}{*}{ d-spacing $(\AA ̊)$} & \multicolumn{3}{|c|}{ a-domain } & \multicolumn{3}{|c|}{ R-PZT } \\
\hline & STO (mrad) & PZT (mrad) & & a $(\AA)$ & $\mathrm{b}(\AA ̊)$ & c (̊̊) & $\mathrm{a}(\AA ̊)$ & $b(\AA ̊)$ & $c(\AA \AA)$ \\
\hline $001 \mathrm{R}$ & 13.098 & 12.474 & 4.100 & & & & & & 4.100 \\
\hline $002 \mathrm{R}$ & 26.196 & 24.917 & 2.053 & & & & & & 4.105 \\
\hline $002 \mathrm{~T}$ & 26.196 & 25.603 & 1.998 & 3.995 & & & & & \\
\hline \multirow[t]{10}{*}{$003 \mathrm{R}$} & 39.294 & 37.423 & 1.367 & & & & & & 4.100 \\
\hline & & & \multicolumn{7}{|c|}{ STEM } \\
\hline & & & \multicolumn{2}{|l|}{ a-domain } & \multicolumn{2}{|c|}{ c-domain } & \multicolumn{3}{|c|}{ R-PZT } \\
\hline & & & $\mathrm{a}(\AA)$ & $c(\AA)$ & $\mathrm{a}(\AA)$ & c ( $\AA$ ) & $\mathrm{a}(\AA ̊)$ & $\mathrm{b}(\AA)$ & $c(\AA \AA)$ \\
\hline & & & 3.975 & 4.104 & 4.051 & 4.196 & 4.097 & 4.077 & 4.116 \\
\hline & & & 3.935 & 4.116 & 4.044 & 4.118 & 4.108 & 4.124 & 4.092 \\
\hline & & & \multicolumn{7}{|c|}{ Average } \\
\hline & & & \multicolumn{2}{|c|}{ a-domain } & \multicolumn{2}{|c|}{ c-domain } & \multicolumn{3}{|c|}{ R-PZT } \\
\hline & & & a $(\AA)$ & $c(\AA)$ & $\mathrm{a}(\AA)$ & $c(\AA)$ & $\mathrm{a}(\AA ̊)$ & $\mathrm{b}(\AA)$ & $c(\AA \AA)$ \\
\hline & & & 3.975 & 4.110 & 4.048 & 4.157 & 4.103 & 4.086 & 4.108 \\
\hline
\end{tabular}



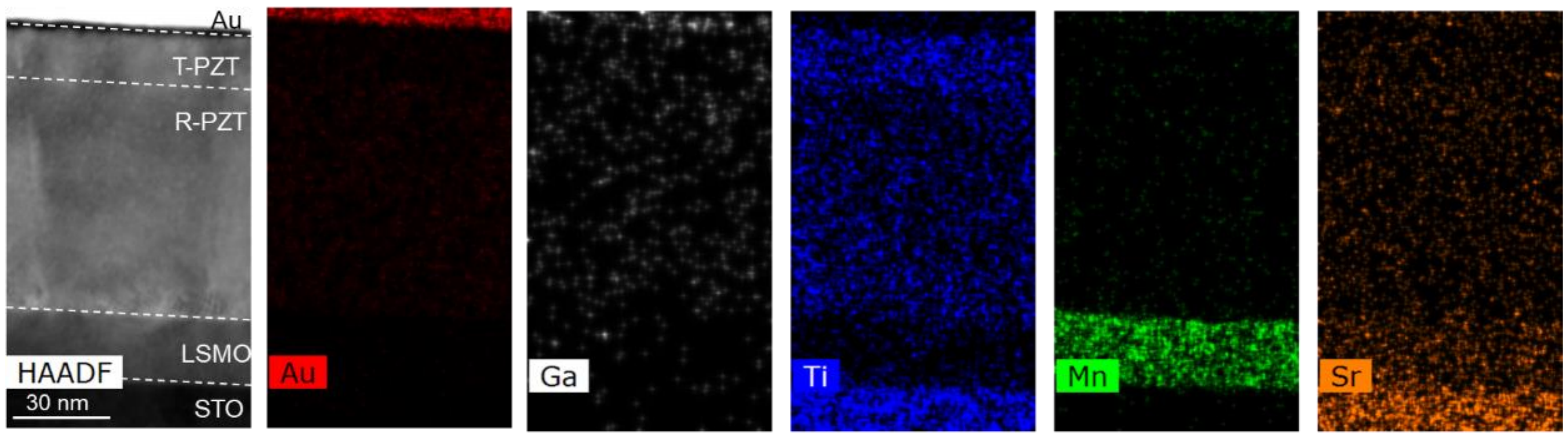

Figure S12. HAADF STEM image and EDS elemental mapping 

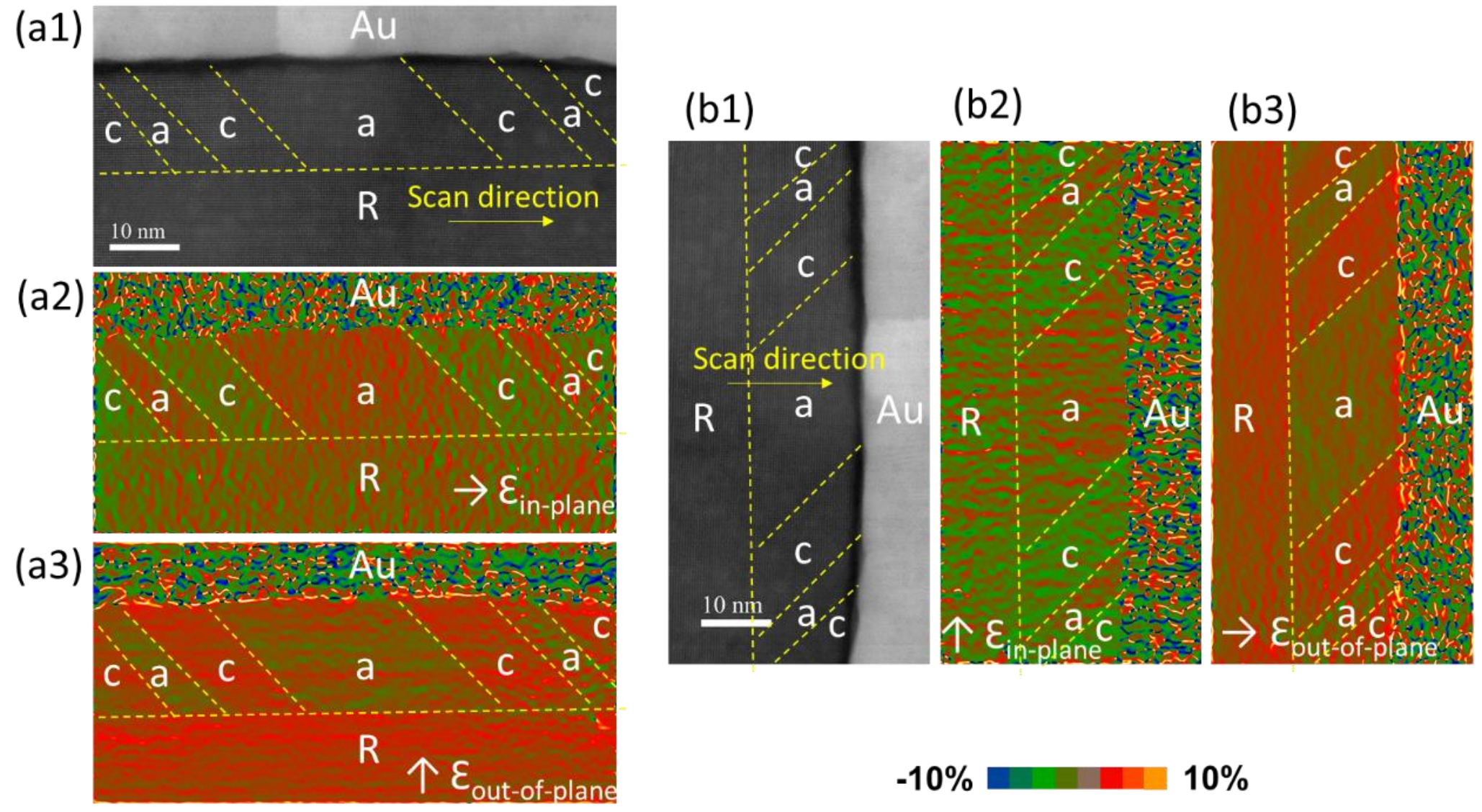

Figure S13. (a1) and (b1) are HAADF images captured the same area but the scan directions rotate $90^{\circ}$ relatively. (a2) and (a3) are GPA strain maps of Figure (a1). (b2) and (b3) are GPA strain maps of Figure (b1). 
(a)

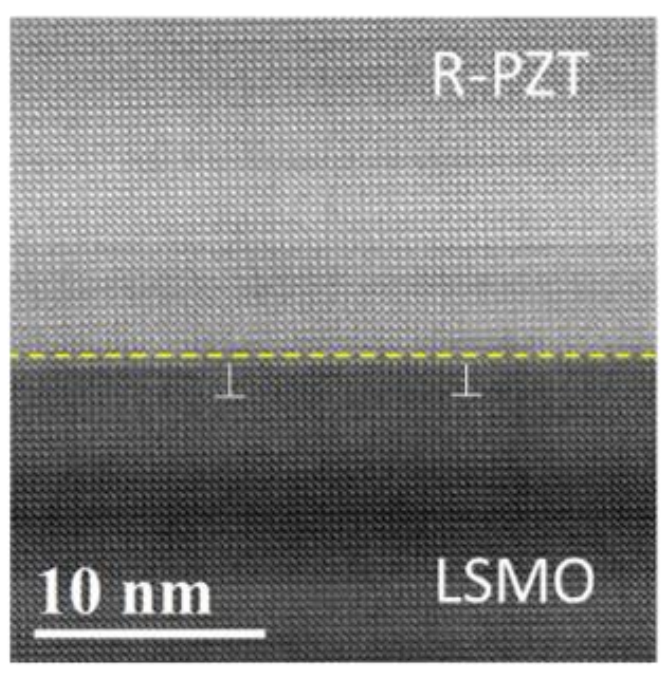

(b)

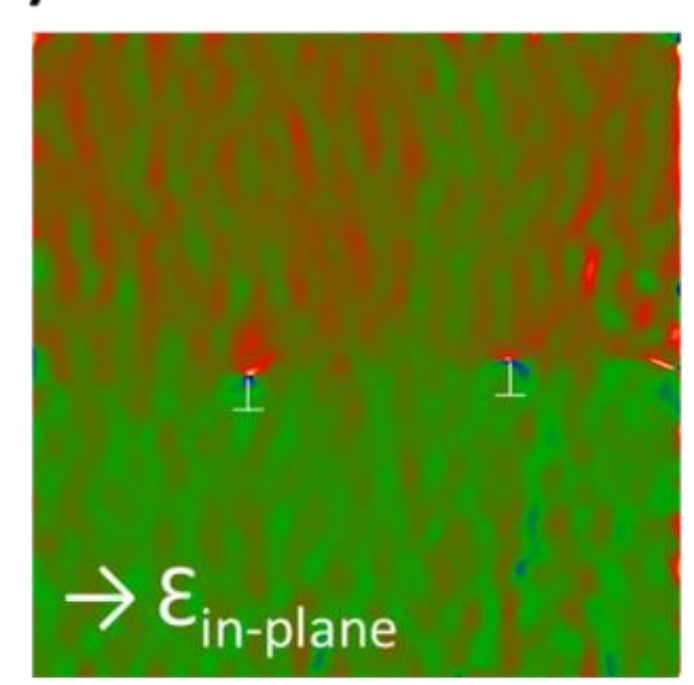

(c)

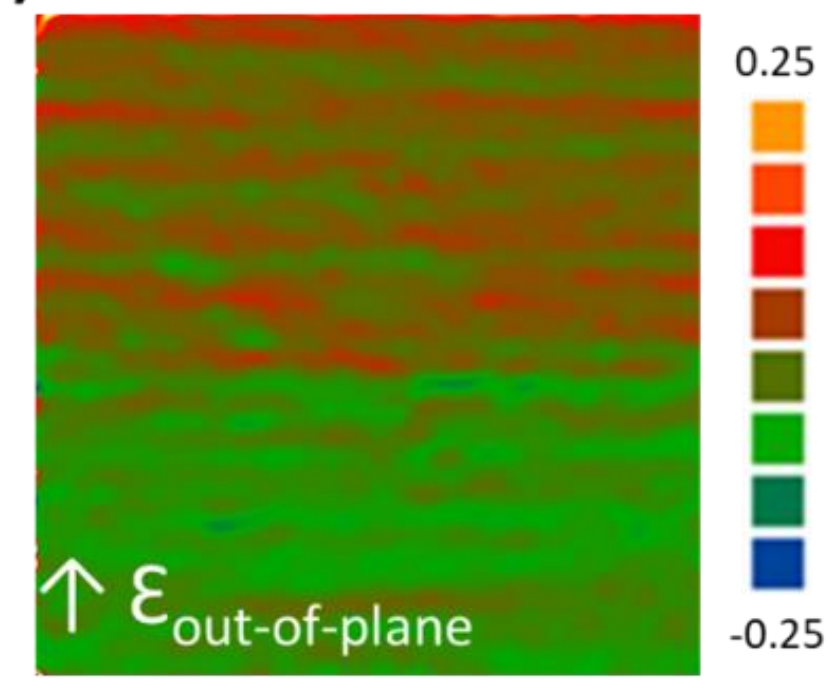

Figure S14. (a) HAADF STEM image near the R-PZT/ LSMO interface. (b) and (c) are in-plane and out-of-plane strain maps obtained from (a) by the GPA method. 
(a)
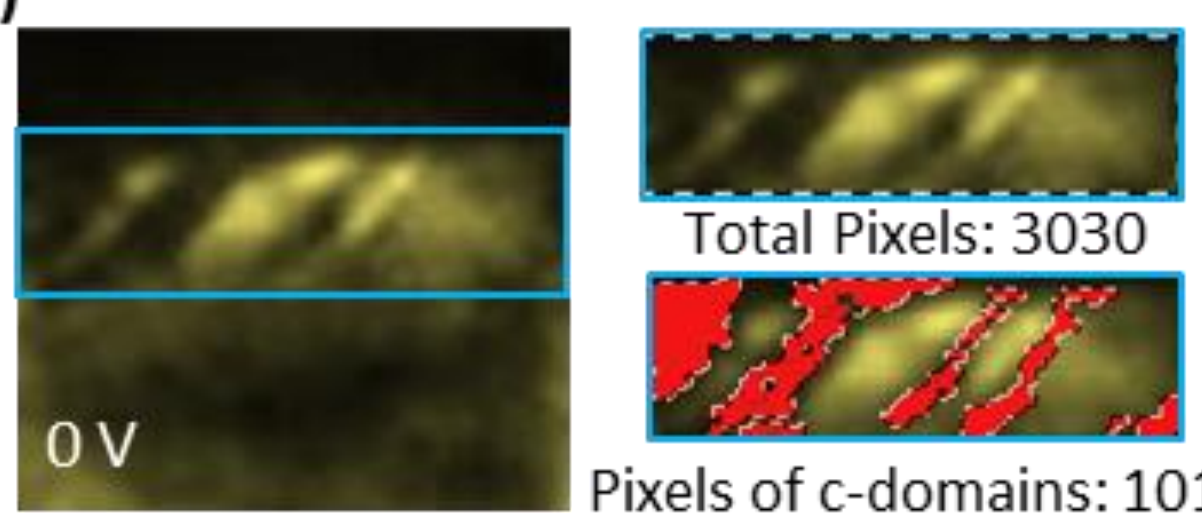

Total Pixels: 3030

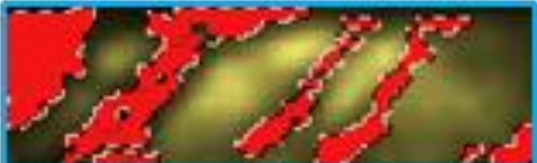

Pixels of c-domains: 1013

(b)

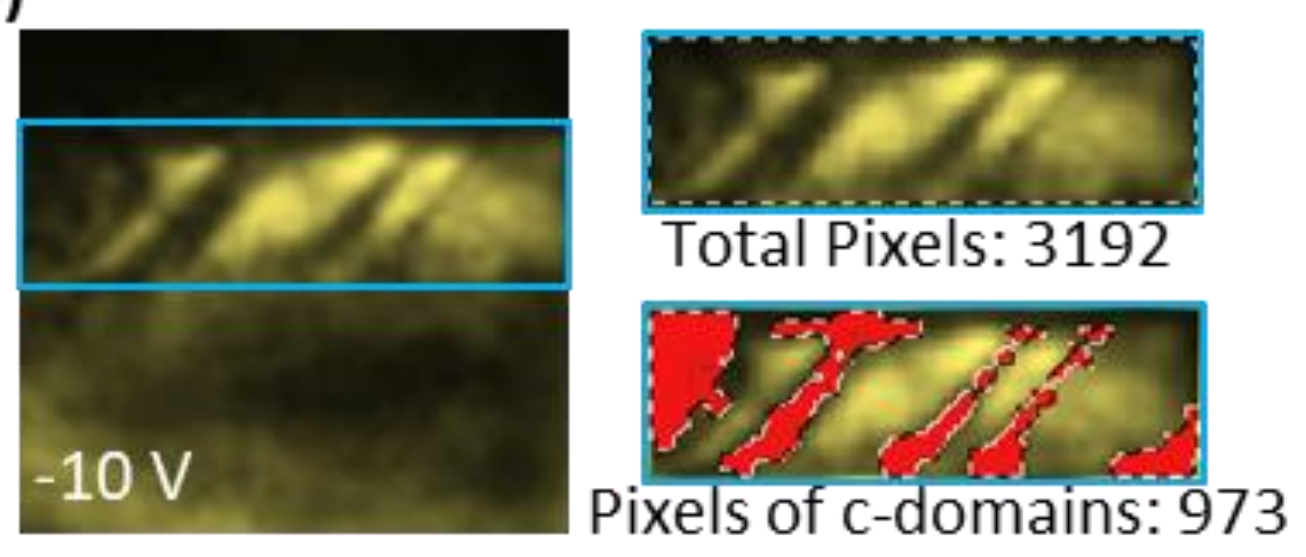

Figure S15. (a) and (b) are dark field images of the same area near the T-PZT and R-PZT interface before bias is applied and after domain structure is restored at $-10 \mathrm{~V}$. Pixels in the T-PZT layer are counted and c-domains are denoted in red color. According to the measurement, the a/c area ratio for the area is (3030-1013): 1013 1.99 before biasing and (3192-973): 973 2.28 after the restoration. The a/c ratio in this region remains around 2 . 